\title{
Cognitive Processes Involved in the Motor Control of Basketball
}

\author{
Pablo Camacho Lazarraga* \\ Centro Universitario San Isidoro, Seville, Spain
}

Received: 眥 August 20, 2018; Published: 阱 September 05, 2018

*Corresponding author: Pablo Camacho Lazarraga, Centro Universitario San Isidoro, Seville, Spain

\begin{abstract}
Is There an Ideal Execution Model in Basketball Individual Skills?

Highly skilled players execute motor skills in a variety of ways, and in many cases different from those described in the technical manuals. However, its execution is characterized in all cases by having a very high degree of effectiveness. What is the reason? Is there then more than one ideal model of movement? A more in-depth analysis of the techniques used would lead us to conclude that in the technical execution of all experts there are a few common, basic and fundamental elements. That is why we must determine those aspects that must always be carried out in the same way. We will call these elements key elements. Once these elements are detected, the practice activities must, through repetition, ensure their automation. The rest of the practice conditions must be very varied, in order to facilitate the possibility of adapting it to different contexts, that is, we must enhance the variability around the stable and repetitive execution of a series of fundamental aspects. The perfection of the automatism does not reside in the invariable linkage of the muscular actions, but, on the contrary, in its possibilities of reorganization in all the instants of the execution and in the course of the successive executions.
\end{abstract}

Keywords: Cognitive Processes; Motor Control; Basketball; Skill; Performance

\section{Introduction}

Traditionally, the apprentice has been considered a black box system, assimilated with a computer, which was entered daily and was able to perform as expected. The individual became a mere recipient of stimuli and response system. The coach did not worry too much about how the players assimilated, stored and controlled their movements. He only worried about transmitting the information he had. Currently the player is not considered a black box impossible to penetrate (translucent or determined box system), the player is not only composed of stimulus receptors and response mechanisms, that is, we can understand how he learns and optimizes his actions Sports. As Ruíz [1] says, we have gone from an orientation based on the product (result) to an orientation based on the study of motor learning processes. But how have these two methodological conceptions influenced the analysis of the individual foundations of the game? Traditionally, a sequential analysis was made of what was intended to be taught, it was based on the search for a model, usually an elite player, defined the execution of the movement by that player as an ideal, and finally fixed and taught its sequence as the most optimal and correct.

\section{But Should We Force A Hypothetically Correct Behavior?}

Riera [2] tells us that there are infinite ways of walking, running and jumping... but you should not force all the trainees to reproduce the same movements, it is necessary to grant a certain freedom so that each one of them can find the set of actions that best suits your conditions.

\section{What Do We Understand Then by Good Technique?}

Knapp [3] tells us that good technique refers to fundamental things rather than details and must be determined in relation to the concrete individual. A suitable technique for one can be a limiting factor for another with different physical or psychological qualities. Good and proper technique is discussed when they achieve the optimum biomechanical level at each moment, a high degree of virtuosity, stability, variable use and the sporting result pursued [4]. Schonborn [5] in his definition of the principle of individuality, tells us that every person constitutes an independent, incomparable unit, composed of many physical and psychic factors that, all together, form their unique and unrepeatable individuality. We must then respect the individual expression, we do not refer 
to a total freedom in the succession of the movement, but to that said succession must be determined by scientific observers, theoretical reflections and practical experiences that, in turn, will be characterized by anatomical-functional aspects, by rules of sports mechanics (biomechanics), by psychic features, by skills and abilities of physical preparation and coordination, by the mechanisms of control of the central nervous system and by sensory and cognitive capacities. But to what extent should the freedom of movement of the player be accepted without exerting a negative influence on the prefixed parts of the execution of the movement?

a) Let's give an example: Highly skilled players execute motor skills in a variety of ways, and in many cases different from those described in the technical manuals. However, its execution is characterized in all cases by having a very high degree of effectiveness. What is the reason? Is there then more than one ideal model of movement? A more in-depth analysis of the techniques used would lead us to conclude that in the technical execution of all experts there are a few common, basic and fundamental elements. That is why we must determine those aspects that must always be carried out in the same way. We will call these elements key elements. Once these elements are detected, the practice activities must, through repetition, ensure their automation. The rest of the practice conditions must be very varied, in order to facilitate the possibility of adapting it to different contexts, that is, we must enhance the variability around the stable and repetitive execution of a series of fundamental aspects.

The perfection of the automatism does not reside in the invariable linkage of the muscular actions, but, on the contrary, in its possibilities of reorganization in all the instants of the execution and in the course of the successive executions [6]. But, what are these fundamental aspects that we must repeat? What elements should we consider key or invariable in the execution of the different foundations? In short, what should we teach? Currently a functional analysis of the fundamentals of the game is carried out. The aims and objectives of each movement are checked, the preconditions to achieve these ends, all based on the theory of movement, the optimal succession of the movement is projected and defined, and finally the high-level players are analyzed according to these criteria. For all this it becomes necessary to know how our players assimilate, control and store the movements.

\section{Theories about Motor Control}

\section{First Hypothesis: Hypothesis of Ecological Theorists}

Peripheral motor control system in closed circuit [7]. The players control their movements thanks to the sensory feedback mechanisms (messages that inform the systems of motor regulation of the subject of their internal state in reference to the movement produced and their relations with the environment continuously). Motor skills are stored in the form of perceptual traces in memory. There are as many perceptive strokes in memory as skilled movements are mastered. It is a cyclical process in which the mental representation of the expected movement (memory trace) is compared with the information contained in the sensory feedback (perceptual trace). Ruíz \& Sánchez [8] tells us that this model is applicable to those tasks in which the continuity of the action and the required rhythm of execution allow the use of sensory feedback during the development of the same. Most of the orders are given throughout its execution. But do the players control all the movements in the same way? What happens when the movements are fast? What kind of control regulates these actions? These same authors affirm that there are sports movements that, due to their speed, make it impossible to regulate them moment to moment, via sensory feedback, and therefore they will demand a prior programming of the same. Most orders are given before the start of the execution of the skill. This set of commands is called the motor program, and its function is the regulation and control of the response.

\section{Second Hypothesis: Hypothesis of The Motor Theorists}

Open circuit motor control system [9]. It defends that there is an unlimited number of internal models of movements stored in memory (motor programs), which are associated with sensory information. The motor program is a kind of physical image. It is the cognitive structure of a gesture once automated. The motor programs are organized sets of commands in the memory necessary for the action, whose deployment does not require the participation of feedback. There are as many motor programs stored in the memory as actions were possible to be performed. Each action will claim its own specific motor program. It is a linear process in which the movement is so fast that it does not allow the comparison and correction processes proper to motor control in a closed circuit to take place.

\section{Third Hypothesis}

Discontinuous or hybrid motor control system [7]. Motor control does not refer only to an isolated movement, but also manifests itself in the development of a sequence or motor sequences, with their different critical phases, with a view to achieving a goal that can change constantly. But two problems arise, the first, can players store all the movements learned? Ruíz and Sánchez [8] affirm that players hardly make the same gesture twice exactly the same, therefore they are generating constant adaptations that can be considered new variations of the same theme, which are definitely new movements. And a second problem, how can players perform movements that have not previously been practiced? How can we explain the versatility and flexibility of human motor behavior?

\section{The Scheme Theory}

It is then when the Theory of the Scheme arises [10], which tells us that this knowledge is stored in a generic and schematic way, and not in a specific way. What we store in memory are not specific and specific motor patterns for the execution of a single gesture, but 
generalized motor programs that guide the execution of families of motor skills (general or generalized motor program). This general motor program represents a plan prior to the movement of an adaptive nature, based on skills already learned (motor programs) and adapted to the specific situation. It is responsible for storing the common elements or always present in the execution of a family of skills. It is built in an active and reflective way. It possesses a knowledge that is abstracted from what is common to a set of actions or movements. They do not have all the details of the motor action, but they must be subjected to a process of specification of the parameters (calibration), in which the motor response schemes play a key role. According to Barlet (1932) [11], a person never reproduces an absolutely new movement, nor never repeats absolutely the same movement. But, what then are those common elements that the player abstracts from a set of actions or movements? What are the invariable elements of the motor schema? According to Ruiz [12] these are:

a) Order of actions: time in which each action intervenes and how it alternates with the others.

b) Temporal structure of the contractions: contraction of the same muscle groups in an intensity and average latency and in the same contraction-relaxation alternation.

c) Relative strength: makes the force produced by each muscle group approximately the same test to be tested.

According to Batalla [13] the invariables of the motor scheme are the trajectories of the movement and the rhythms of execution.

\section{Let's Give Some Examples}

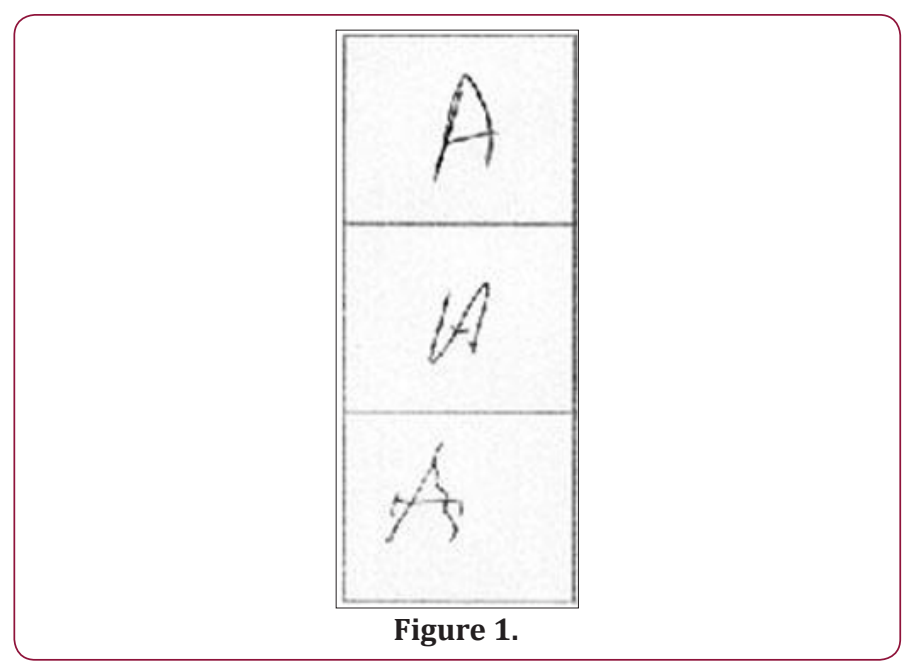

The letters that are shown below have been written by different people. From top to bottom, the first row corresponds to a person of 40 years (my brother), the second row with a person of 74 years (my father), and the last row with a person of 103 years (my grandmother). As we can see, none of these three letters is exactly the same, and yet all of them are valid, they are all the letter "A" (Figure 1). But even if we asked each of these people to write the same letter several times, we would see that none of them would repeat exactly the same, and yet all of them are still valid, all of them are still the letter "A" (Figure 2). Ruiz [12] tells us that the variability of a gesture is produced from a common pattern, which is what is stored. We have already seen that we cannot store all movements in our memory. So, what do we really store? (Figure 3). First, an elevation is made, then a movement in the opposite direction, and finally a transversal one.
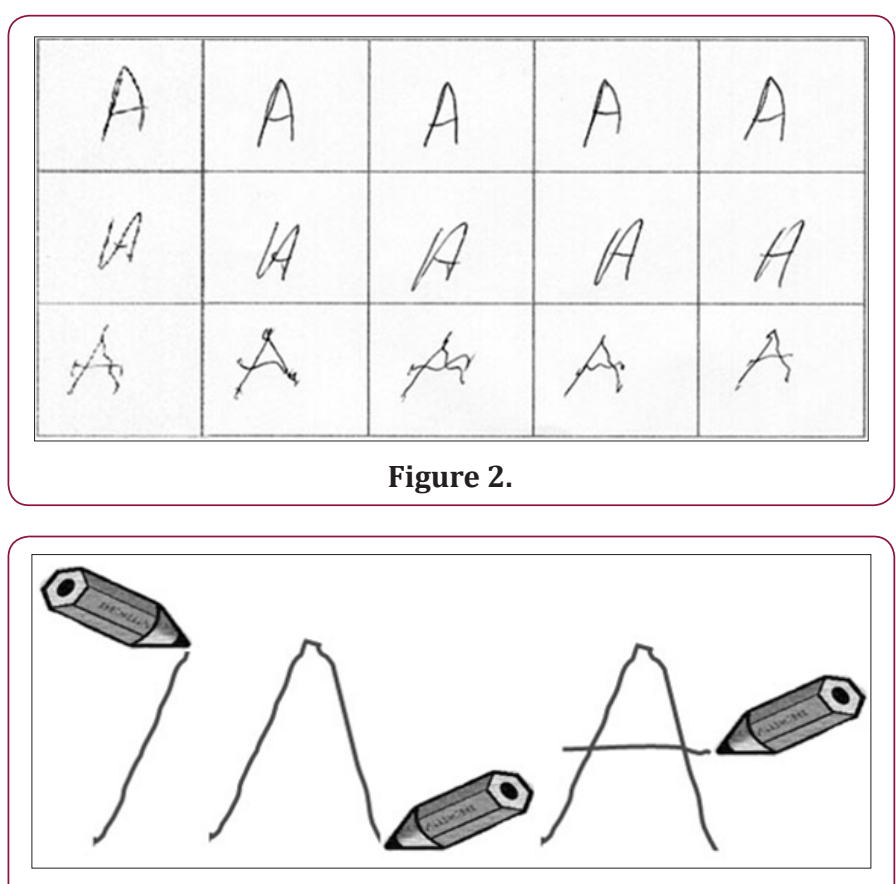

Figure 3.

\section{Let's Take Another Example}

"The level words". Do we memorize all the plain words to know they are? Or do we learn a rule that includes all of them and allows us to recognize them? Rule: accent on the penultimate syllable, flat, grave or paroxitone. Do we now know what to repeat? Are these elements invariable of the motor scheme the key elements that we must teach? Were those foundations executed by experts, all characterized by a high degree of effectiveness, so different? Or did they all share the invariable or key elements that are the fundamental backbone of the execution of these movements? That is, players must reproduce the essentials ... to produce their own. Once the general engine program of the movement class that is being executed has been selected, the player must specify it in each of its parameters so that it becomes an adaptive behavior (calibration process). Quickly or slowly, with more or less force, etc. [7]. Who is responsible for regulating these parameters? It is when the notion of Response Scheme is introduced, that it is a set of rules that allow us to contextualize our motor activity, that is, to apply it in a varied way according to the concrete conditions of execution [10]. That is, when we learn to throw a ball, we will not memorize the force that we must use from each distance, but a rule that relates both parameters. Therefore, it is the Motor Response Scheme that converts the General Motor Program into an adaptive 
behavior for the achievement of an objective. This scheme arises from the abstraction of information from multiple sources [14]:

a) Initial conditions prior to the response.

b) Response specifications.

c) Sensory consequences of the answers.

d) Results obtained by the answers.

The player abstracts the existing relationships between these four sources of information, progressively configuring the response rule-schema. This schema-rule, therefore, is inferred from past experiences.

\section{Conclusion}

In the sports of collective interaction, where the skills that are executed are predominantly perceptive, the execution process has a high dependence on the processes of perception and decision, so we must take into account especially the development of these two mechanisms. That is why we cannot speak of an ideal execution model, as we have mentioned before, this will depend on the environment where it is developed. We must respect the individual expression of the players, determined by scientific observers, theoretical reflections and practical experiences that, in turn, will be characterized by anatomical-functional aspects, norms of sports mechanics (biomechanics), psychic traits, skills and preparation skills. physics and coordination, control mechanisms of the central nervous system and sensory and cognitive capacities.

\section{ISSN: 2574-1241}

DOI: $10.26717 / B J S T R .2018 .08 .001690$

Pablo Camacho Lazarraga. Biomed J Sci \& Tech Res

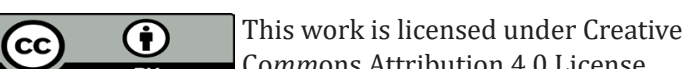

Submission Link: https://biomedres.us/submit-manuscript.php

\section{References}

1. Ruiz LM (1994a) Factores que influyen en el aprendizaje motor. Apunts 38: $34-40$

2. Riera J (1989) Fundamentos del aprendizaje de la técnica y la táctica deportivas. Barcelona: Inde.

3. Knapp B (1979) La habilidad en el deporte. Valladolid: Miñón.

4. Martin D, Carl K, Lehnertz K (2001) Manual de metodología del entrenamiento deportivo. Barcelona: Paidotribo.

5. Schonborn R (1999) Tenis: Entrenamiento técnico. Tutor, Madrid, pp. 288.

6. Le Boulch J (1978) Hacia una ciencia del movimiento humano. Buenos Aires: Paidós.

7. Ruiz LM (1994b) Deporte y aprendizaje. Procesos de adquisición y desarrollo de habilidades. Visor, Madrid, pp. 288.

8. Ruiz LM, Sánchez F (1997) Rendimiento deportivo. Claves para la optimización de los aprendizajes. Gymnos, Madrid.

9. Boné A (1998) Modelos de interpretación del aprendizaje motor Los modelos cibernéticos. En A. Boné, Manual del técnico deportivo. Segundo nivel. Zaragoza: Mira, pp. 327-331.

10. Schmidt RA (1975) A schema theory of discrete motor skill learning. Psychological Review 82(4): 225-260.

11. Lawther J (1968) Aprendizaje de las habilidades motrices. Barcelona: Paidós.

12. Ruiz LM (1995) Competencia motriz. Elementos para comprender el aprendizaje motor en educación física escolar. Gymnos, Madrid.

13. Batalla A (2000) Habilidades motrices. Barcelona: Inde.

14. Díaz J (1999) La enseñanza y aprendizaje de las habilidades y destrezas motrices básicas. Barcelona: Inde.

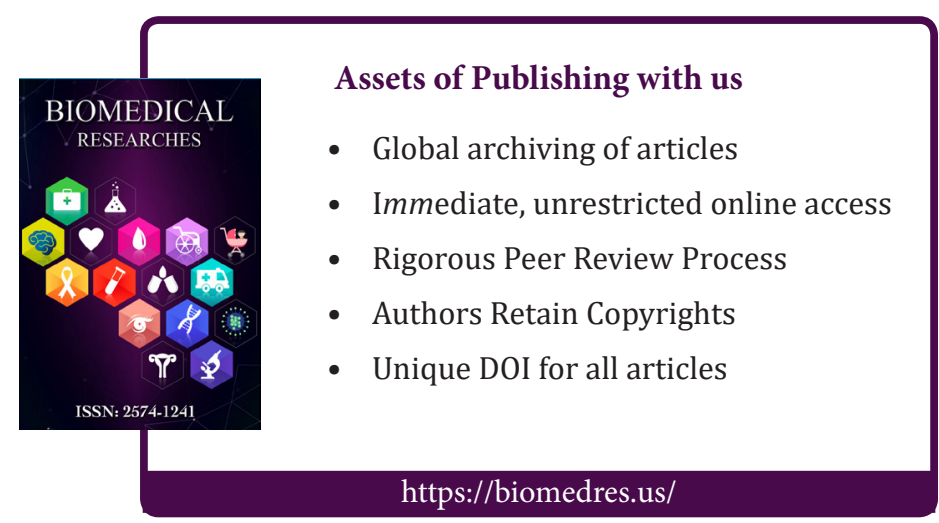

